\title{
Telemedicine as the New Outpatient Clinic Gone Digital: Position Paper From the Pandemic Health System REsilience PROGRAM (REPROGRAM) International Consortium (Part 2)
}

\author{
Sonu Bhaskar ${ }^{1,2,3,4 *}$, Sian Bradley ${ }^{1,5}$, Vijay Kumar Chattu 1,6,7, Anil Adisesh ${ }^{1,6,7}$, \\ Alma Nurtazina ${ }^{1,8}$, Saltanat Kyrykbayeva ${ }^{1,8}$, Sateesh Sakhamuri, ${ }^{1,9}$, \\ Sebastian Moguilner ${ }^{1,10}$, Shawna Pandya ${ }^{1,11}$, Starr Schroeder ${ }^{1,12}$, Maciej Banach ${ }^{1,13,14,15}$ \\ and Daniel Ray ${ }^{1,16}$
}

\section{OPEN ACCESS}

Edited by:

Alberto Eugenio Tozzi.

Bambino Gesù Children Hospital (IRCCS), Italy

Reviewed by:

David Charles Willis,

Strides Toronto, Canada

Pekka Lahdenne,

Helsinki University Central

Hospital, Finland

${ }^{*}$ Correspondence: Sonu Bhaskar

sonu.bhaskar@health.nsw.gov.au

Specialty section:

This article was submitted to

Digital Public Health,

a section of the journal

Frontiers in Public Health

Received: 30 April 2020

Accepted: 10 July 2020

Published: 07 September 2020

Citation:

Bhaskar S, Bradley S, Chattu VK

Adisesh A, Nurtazina A

Kyrykbayeva S, Sakhamuri S, Moguilner S, Pandya S, Schroeder S,

Banach M and Ray D (2020)

Telemedicine as the New Outpatient

Clinic Gone Digital: Position Paper

From the Pandemic Health System

REsilience PROGRAM (REPROGRAM)

International Consortium (Part 2).

Front. Public Health 8:410.

doi: 10.3389/fpubh.2020.00410
${ }^{1}$ Pandemic Health System REsilience PROGRAM (REPROGRAM) Consortium, REPROGRAM Telemedicine Sub-committee, Sydney, NSW, Australia, ${ }^{2}$ Department of Neurology, Liverpool Hospital and South Western Sydney Local Health District, Sydney, NSW, Australia, ${ }^{3}$ Neurovascular Imaging Laboratory \& NSW Brain Clot Bank, Ingham Institute for Applied Medical Research, Sydney, NSW, Australia, ${ }^{4}$ South Western Sydney Clinical School, The University of New South Wales, UNSW Medicine, Sydney, NSW, Australia, ${ }^{5}$ The University of New South Wales (UNSW) Medicine Sydney, South West Sydney Clinical School, Sydney, NSW, Australia, ${ }^{6}$ Department of Medicine, University of Toronto, Toronto, ON, Canada, ${ }^{7}$ St. Michael's Hospital, Toronto, ON, Canada, ${ }^{8}$ Department of Epidemiology and Biostatistics, Semey Medical University, Semey, Kazakhstan, ${ }^{9}$ Department of Clinical Medical Sciences, The University of the West Indies, St. Augustine, Trinidad and Tobago, ${ }^{10} \mathrm{Global}$ Brain Health Institute, Trinity College Dublin, Dublin, Ireland, ${ }^{11}$ Alberta Health Services and Project PoSSUM, University of Alberta, Edmonton, AB, Canada, ${ }^{2}$ Penn Medicine Lancaster General Hospital and Project PoSSUM, Lancaster, PA, United States, ${ }^{13}$ Polish Mother's Memorial Hospital Research Institute (PMMHRI), Łódz, Poland,

${ }^{14}$ Cardiovascular Research Centre, University of Zielona Gora, Zielona Gora, Poland, ${ }^{15}$ Department of Hypertension, Medical University of Lodz, Łódz, Poland, ${ }^{16}$ Farr Institute of Health Informatics, University College London (UCL) \& NHS Foundation Trust, Birmingham, United Kingdom

Technology has acted as a great enabler of patient continuity through remote consultation, ongoing monitoring, and patient education using telephone and videoconferencing in the coronavirus disease 2019 (COVID-19) era. The devastating impact of COVID-19 is bound to prevail beyond its current reign. The vulnerable sections of our community, including the elderly, those from lower socioeconomic backgrounds, those with multiple comorbidities, and immunocompromised patients, endure a relatively higher burden of a pandemic such as COVID-19. The rapid adoption of different technologies across countries, driven by the need to provide continued medical care in the era of social distancing, has catalyzed the penetration of telemedicine. Limiting the exposure of patients, healthcare workers, and systems is critical in controlling the viral spread. Telemedicine offers an opportunity to improve health systems delivery, access, and efficiency. This article critically examines the current telemedicine landscape and challenges in its adoption, toward remote/tele-delivery of care, across various medical specialties. The current consortium provides a roadmap and/or framework, along with recommendations, for telemedicine uptake and implementation in clinical practice during and beyond COVID-19.

Keywords: coronavirus disease 2019, COVID-19, telemedicine, telerehabilitation, telepsychiatry, teleneurology 


\section{INTRODUCTION}

Coronavirus disease 2019 (COVID-19) has challenged the status quo of how we approach, deliver, and receive modern medicine (1-4). According to the American Telemedicine Association, telemedicine is defined as "the remote delivery of healthcare services and clinical information using telecommunications technology" (5). It allows for patient care while minimizing the need for physical interaction, thus reducing infection transmission and healthcare facility burden. It can be utilized for ongoing management of chronic conditions, medication compliance, physician-topatient consultation, and other remote services $(3,4)$. This can be leveraged to benefit broader populations through telehealth platforms and assisted technologies such as the Internet of things (IoT). Telemedicine and digital technologies demonstrate exceptional potential in improving access and delivery in remote settings. There is also an opportunity to exploit the power of artificial intelligence (AI) algorithms to design a better pandemic preparedness and response plan (6). Health systems have had to adapt to address emerging needs quickly, and many medical subspecialties have transitioned from in-person outpatient care to remote tele- or e-health.

Broadly, telehealth technologies can be deployed for targeted purposes relevant to a pandemic (7). Remote assessment of patients could be undertaken, circumventing visits to outpatient clinics or primary care providers. Patient continuity for those with chronic diseases is essential during a pandemic $(3,4)$. Such patients are also at high risk of infection and poor outcomes, including mortality, among COVID-19-positive patients (3). Notably, telemedicine also limits infection exposure to healthcare staff, can provide rapid access to subspecialists who are not immediately available in person, and allows for multidisciplinary team discussions. This is crucial in pandemic settings, as the safety of healthcare professionals is essential to ensure the sustainability of health systems to cater to emergent cases and maintain ongoing care. Patients with flu-like symptoms can be triaged, and telemonitoring using video surveillance could be considered for patients who are homebound such as the elderly or frail.

Telemedicine can increase access for certain populations who are challenged during limited healthcare facility visitation, stay-home orders, and quarantine, such as single parents, immunocompromised patients, and patients who rely on the assistance of others for transportation. Monitoring of patients along with remote delivery of home-based exercise, physiotherapy, psychological counseling, social work consultations, and speech and language interventions could be undertaken through telemedicine. Our previous work analyzed the status and deployment of telemedicine during COVID-19 across the geographical divide (Bhaskar et al., under review). In this article, we analyze the uptake of telemedicine across various medical subspecialties and organizational settings with a focus on the current COVID-19 pandemic and propose an operational roadmap for further integration of telemedicine or tele-technologies across health organizations.

\section{TELEMEDICINE IN EMERGENCY CASES AND TRIAGE}

As hospital systems become strained by the surge of COVID19 patients, methods to improve the efficiency of emergency departments (EDs) are required, while maintaining standards of patient care. Telemedicine supplies a potential avenue for triage of critical cases. Remote and ambulatory monitoring of patients can allow for remote triage and assessment of emergencies such as acute myocardial infarction (MI), allowing patients to bypass the ED (8). Automated forward triage systems that use algorithms to categorize patients into risk groups could also be utilized, as ED physicians experience considerable time pressure. Current examples include the Multi Sources Healthcare Architecture (MHSA) algorithm and the Electronic Modified Early Warning Scorecard (9). Telemedicine has also been used to triage, expedite, and streamline the local COVID-19 screening process, thereby reducing the strain on healthcare facilities and practitioner exposure.

The New York Presbyterian Hospital, a world leader in digital health innovation, has demonstrated an effective method to reduce the burden of milder presentations (10). They established an ED-based Telehealth Express Care Service, in which after presentation and triage at the $\mathrm{ED}$, patients with milder cases are taken into a private room for a teleconsultation with a physician. Prescriptions and patient instructions are then printed to the room, and the patient is discharged. This dramatically reduces ED waiting times and allows the hospital to deal with everincreasing ED presentation numbers (10). As patients become anxious about ED infection risk, systems such as these are required, and patients need to be able to effortlessly contact EDs to query whether their symptoms require a presentation.

\section{Telecardiology}

Cardiology is one of the first specialties in which comprehensive telemedicine systems have been implemented. Monitoring of heart rhythm in patients with implanted or real-time wearable devices has allowed ECG with Holter monitoring, echocardiography records, and virtual auscultation. An emerging body of evidence suggesting cardiac involvement in COVID19 patients has concerned cardiologists $(3,11)$. This includes cardiovascular complications such as cardiac injury, heart failure, myocarditis, pericarditis, vasculitis, and arrhythmias (12-14). Patients with pre-existing cardiovascular conditions who contract COVID-19 also experience inordinately poor outcomes, including a 5- to 10-fold rise in mortality (15). Due to the COVID-19 pandemic, the American College of Cardiology urgently updated its guidance on "Telehealth: Rapid Implementation for Your Cardiology Clinic," in which it encouraged remote monitoring and virtual visits of patients with cardiac problems (16). The development of prognostic models based on the recently launched new European register CAPACITY-COVID will help to understand the role of underlying cardiovascular disease (CVD) in patients with COVID-19 (17).

Virtual options can significantly increase efficiency compared to in-person doctor appointments (18). Notably, non-invasive 
telemonitoring in patients with heart failure reduces allcause mortality and number of hospitalizations, as well as improves the quality of life (19). In February 2020, the Italian Society of Cardiology published data on the implementation of telemedicine in CVD patients and reported crucial involvement of telemedicine in the prehospital triage for ST-elevated myocardial infarction (STEMI) cases and remote monitoring by primary care physicians (20). An American Heart Association (AHA) statement emphasized the role of telemedicine in pediatric cardiology through advanced video technologies like tele-echocardiography, fetal echocardiography in prenatal diagnosis, screening for congenital heart diseases, and confirmatory echo tests, external rhythm monitoring, catheterization laboratory, and personal tele-electrophysiology (21). Due to their comorbidity risk, efforts to prevent COVID19 infection in CVD patients should be undertaken seriously by reducing hospital admission and outpatient visits (3).

Treatment adherence is one of the significant issues in the long-term management of CVDs (22). The utilization of mobile phones through mobile health (Mhealth) can be one of the reliable potential solutions in this area through measures such as electronic pillboxes and text reminders (22). The unique advantage of portable devices and smartphones is the ability to reach most patients and caregivers. The widespread use of mobile technologies makes medical support more effective, faster, safer, and less expensive in both outpatient and inpatient settings (23). Mhealth can play an increasingly important role in cardiac care, extensively applied in triage, interventions, management, patient education, and rehabilitation. Telehealth solutions are critical now, as we aim to minimize patients at high and very high cardiovascular risk being hospitalized and provide ongoing support to CVD patients during the COVID19 pandemic. In Poland, some other systems have been tested in heart failure patients $(24,25)$, including e-oximeter, allowing for monitoring of heart rhythm and blood saturation, which might help to decide whether those quarantined should be hospitalized during COVID-19.

\section{Tele-Acute Neurology}

Telemedicine allows for prompt assessment of potential emergent neurological cases and can aid those with hospital access issues and those requiring fast acute assessment $(2,4)$. Acute stroke outcomes are vastly impacted by the speed at which treatment is given, whether it be through tissue plasminogen activator (tPA), endovascular clot retrieval (EVT), or antihypertensives. During times of physician shortages, as doctors become re-purposed for COVID-19 purposes, rapid approaches to acute stroke management are needed (2). Reperfusion treatment viability through computed tomography (CT) can be assessed remotely, allowing reperfusion treatment using tPA and/or EVT to be efficiently undertaken. Furthermore, telemedicine can be utilized to determine which patients require an urgent transfer from non-EVT-capable hospitals to EVTcapable hospitals (26). A program developed in Germany known as TRANSIT-stroke, in which rural hospitals established a telemedicine network, saw an improvement in patient outcomes as neurological assessment was made faster, treatments were issued within the required timeframe, and $24 \mathrm{~h}$ neurologist access was enabled (27). Similarly, successful programs have been undertaken worldwide, such as telestroke programs in Hawaii and South California (28). There is also evidence to suggest that patients who receive acute stroke assessment through telemedicine do not perceive decreased physician empathy compared to those who receive physical consultation (29). This somewhat relieves concerns about impaired patientphysician connection through telemedicine. While telemedicine decreases the time it takes to analyze head CTs, more work is needed to ensure that this benefit applies equally across different telestroke programs (30).

Mobile stroke units (MSUs) go beyond this to provide CT scanners and stroke personnel within an ambulance vehicle. Such programs exist in locations such as Melbourne (Australia), various states in the US, and Hamburg and Berlin (Germany), among others (31). MSUs improve acute ischemic stroke outcomes by reducing the time to reperfusion; however, further development is needed in the treatment of hemorrhagic stroke. Telemedicine could also allow CT assessment of mild traumatic brain injuries (such as concussions). This can help to determine if the patient requires transfer to a major hospital or can be treated locally and will also allow for post-concussion checkups (32).

\section{TELEMEDICINE IN CRITICAL CARE AND RESPIRATORY MANAGEMENT WITH AN EMPHASIS ON COVID-19}

Vulnerable patients who require respiratory management and/or critical care are at increased COVID-19 risk due to their impaired state and require effective management with the aid of technology (33). In 2019, the Society of Critical Care Medicine (SCCM) Tele-ICU Committee in the United States published an update on developments in telehealth critical care (TCC) (34). They described three emerging trends in TCC: hub-andspoke structure in which a central hub provides remote technical support, administrative support, and integration to a network of hospitals; decentralized structures in which consultations and patient reviews will be made on a case-by-case and request basis between two sites; and a hybrid structure in which a centralized structure exists but direct contact between spokes can be made for, e.g., specialist consultations. Barriers to TCC included cost and reimbursement issues, lack of responsibility for individual hospitals, and legislative issues (34).

A 2012 systematic review and meta-analysis of telemedicine in the US intensive care unit (ICU) setting demonstrated decreased mortality and length of hospital stay with telemedicine incorporation (35). However, a statistical difference between an active model or high-intensity passive model, in which continuous patient telemonitoring is conducted, and a lowintensity passive model, in which only teleconsultation with an intensivist is conducted, was not ascertained and is an area for further research (35). Patients with respiratory issues are at higher risk of COVID-19 severe infections due to issues such as ventilator reliance and decreased cough function (33). This includes patients with chronic respiratory 
conditions such as chronic obstructive pulmonary disease (COPD), bronchial asthma, interstitial lung diseases, as well as chronic neurological conditions such as neuromuscular diseases $(33,36)$. Telemedicine aids respiratory patients through data collection, such as monitoring of vitals and ventilator status, and by transmitting these data for constant monitoring. In the case of under-resourced or under-developed critical care units in low and middle-income countries (LMICs) (Bhaskar et al., under review), frequent international tele-education can serve to upskill doctors and spread critical care knowledge, such as ventilator management (37).

\section{CHRONIC DISEASE, PRIMARY CARE, AND THE NEED TO FOCUS ON NON-ACUTE CARE}

Patients with non-acute diseases require ongoing support and cannot be neglected during COVID-19 times (1, 3, 4, 33). Studies have shown that telemedicine can lead to similar outcomes as face-to-face delivery of care in the management of patients with heart failure, hypertension, and diabetes $(38,39)$. Ongoing monitoring of these patients is required to prevent acute manifestations, hospitalization, or disease progression $(3,4)$. The differences within medical subspecialties and individual patients need to be considered, rather than broadly implementing uniform telemedicine approaches across all departments. For example, infectious disease cases can be complicated and require careful consideration of patient history and investigation findings. In these cases, asynchronous consultations, in which the physician reviews data before supplying patient recommendations, will be helpful (40). In other fields such as neurology, cardiology, and endocrinology, realtime, interactive consultations might be more applicable $(3,4)$.

Patients with neuromuscular issues are particularly at risk due to COVID-19 (4). Patients with motor neuron disease (MND)/amyotrophic lateral sclerosis (ALS) are among those who experience considerable disability and will require multidisciplinary telehealth (4). Types of telehealth include teleadvice, teleconsultation, tele-prescription, videoconferencing, home-based self-monitoring, and remote non-invasiveventilation (NIV) monitoring. Videoconferencing involves consultation with a health professional, home-based selfmonitoring involves taking one's own measurements and submitting them to a physician, and remote NIV monitoring involves remote monitoring of the patient's NIV data (41). The use of telehealth with ALS patients has been shown to be associated with positive benefits such as reasonable adoption rates, personalized data, and efficient consultations (42). Other movement disorders such as Parkinson's disease (PD) also require ongoing multidisciplinary care (43). Established programs such as the Ontario Telemedicine Network, the ParkinsonNet infrastructure in the Netherlands, and that of Kaiser Permanente in the US all display the ability to integrate telehealth into PD patient care (44). Areas for growth include the reimbursement of nursing homes that utilize telemedicine, acceptance by patients and physicians, and reimbursement of at-home telemedicine programs (44).
Furthermore, global partnerships can increase international telehealth integration. For example, the International Parkinson and Movement Disorders Society Africa Section, established in the USA, launched a 5-year program to deliver specialist care to disadvantaged areas in Africa using WhatsApp ${ }^{\mathrm{TM}}$. Diagnosis of PD could also be aided by telehealth, with the Unified Parkinson's Disease Rating Scale (UPDRS) and Montreal Cognitive Assessment (MoCA) for PD both being able to be performed remotely (45). Such tele-tools have also been recently proposed in the times of COVID-19 for familial hypercholesterolemia patients, who require continuous monitoring of their health due to lifelong high levels of cholesterol and increased CVD risk (46). In migraine and headache patients, telemedicine could be used to assess new headache profiles for possible COVID-19 symptomology or standard outpatient consultations $(4,47)$.

Cancer patients are another group at risk of COVID19 infection due to their immunosuppressed states, which could have fatal outcomes subsequent to infection (48-52). Oncologists would use telemedicine for ongoing monitoring and compliance with cancer patients $(49,51)$. This could be useful in monitoring adverse reactions to ongoing chemo- or radiotherapy, as well as to identify patients who might be at high risk of emergent medical attention, such as those at risk of venous thromboembolism. Cancer patients could also be offered multidisciplinary care, including psychological interventions, physiotherapy, and specialized interventions such as mindfulness training, to improve the overall quality of life (49). Overall, telemedicine offers opportunities for cancer patients to access specialist care in the comfort of their homes. Approaches to the use of telemedicine and mobile technologies in increasing access to novel drugs or interventions through clinical trials should be expeditiously pursued. Telemedicine could also be used in palliative care and end-of-life planning involving patients' carers, family, and multidisciplinary care team (53). Teledermatology is another promising perspective in the diagnosis and monitoring of skin lesions, including cancer (54).

Non-acute ophthalmological telemedicine has been implemented for retinal scans relating to diabetic retinopathy, retinopathy of prematurity, and other non-acute retinal monitoring (55). Fundus scanning and optical coherence tomography imaging are being sent to remote trained healthcare practitioners (HCPs) for evaluation and additionally are being evaluated by AI analysis using deep learning. These non-acute services are also being utilized locally by emergency and urgent care services to a certain extent (55).

Chronic patients must adhere to medications during this time and should not stop treatment regimens without consulting their physician $(3,4)$. Patients taking immunosuppressants, steroids, or pain medications may be concerned about their COVID-19 risk, and contact with their physicians needs to be ensured. Adherence to medications can be monitored through Mhealth and telehealth means (56). Such examples include digital adherence technologies (DATs) or electronic directly observed therapy (eDOT) for patients with tuberculosis (56). Measures include ingestible sensors, video observation, digital pillboxes, and smartphone applications and have been trialed in China, India, Belarus, and the US $(56,57)$. 


\section{IDENTIFYING THOSE WITH BULBAR AND RESPIRATORY WEAKNESS}

The European Respiratory Society (ERS) task force has described the implementation of remote home mechanical ventilation and physical therapy for patients with chronic respiratory disorders (58). The emphasis is on promoting common standards of clinical criteria as well as analyzing the cost/benefit ratio and evaluating reimbursing rules to implement in different countries (58). Tele diagnosis uses patient data to aid remote diagnosis and can be utilized to identify those with bulbar and respiratory weakness. Telemedicine strategies such as electronic inhalers, chipped nebulizers, self-monitoring through apps, and text reminders increase medicine compliance in patients with asthma, COPD, and cystic fibrosis (CF) (59). Furthermore, the diagnosis of COPD through telemedicine means such as spirometry tracing and teleconsultation provides an opportunity to utilize technology to increase patient care. Further studies are needed to stratify which patients, in terms of severity, will be best suited to a telemedicine management approach. Another area of potential growth is in using AI algorithms to determine developing COPD exacerbations (60). Telemedicine for asthmatics tends to be more focused on treatment compliance and self-monitoring and can be useful in helping patients learn more about their disease, such as recognizing patterns of asthma triggers (61). Other barriers to care include the risk that patient data may be manipulated, networks potentially becoming compromised, and inconclusive data on the benefit of telehealth on specific diseases such as COPD (62).

Obstructive sleep apnea (OSA) is one such disease in which remote monitoring can be utilized to prevent patients from having to spend time in a sleep clinic or respiratory clinic (63). Home polysomnography devices can be used to track patients' breathing and oxygen levels; however, further work is needed to lower the rate of false negatives to the level of in-person sleep clinics (63). A 2018 prospective study of 780 patients used a portable spirometer, with Bluetooth capabilities and connected to a mobile phone application, to trace results and connect the patient to a physician for analysis (64). This allowed the patient's breathing difficulties to be assessed and categorized as asthma, COPD, or normal breathing function (64). This study shows promising results for remote diagnosis of chronic breathing conditions; however, it does not preclude the need for future testing in some more complicated cases. Other smartphone applications have utilized microphones and questionnaires to analyze and detect breathing difficulties associated with other pulmonary conditions such as coughs and lung cancer (65). COVID-19 could impose severe stress on sleep clinics and may limit in-laboratory polysomnography sleep studies for OSA assessments and diagnosis. Home-based telepolysomnography for OSA assessment could be explored so that the delayed diagnosis and the associated impact on patients could be minimized.

Patients with OSA often require continuous positive airway pressure (CPAP) while sleeping to improve symptoms and achieve proper rest (66). In order to see sustained results, patients need to use CPAP for at least $4 \mathrm{~h}$ at night, combined with lifestyle changes such as weight reduction and smoking cessation (66). Low adherence to CPAP remains a continuous problem for OSA patients due to lack of motivation, discomfort, loud noise, and claustrophobia (67). Telehealth provides an opportunity to increase CPAP adherence by monitoring device output data and patient self-tracking of lifestyle factors. When usage falls, the patient can be contacted to discuss their reasons for low adherence and to motivate them to continue use (68).

Telemedicine could be used to monitor bulbar function in patients with a compromised bulbar function such as ALS $(4,69)$. The rapid decline in bulbar function could be captured using technologies that are useful in delivering specialist multidisciplinary care (69). Other diseases in which bulbar function may be impaired include myasthenia gravis, spinalbulbar muscular dystrophy, and riboflavin transporter deficiency $(4,70-72)$.

\section{TELEMEDICINE-ASSISTED FOLLOW-UP AND REHABILITATION}

Telemedicine can aid with rehabilitation following acute incidents such as stroke and traumatic brain injury (TBI) $(2,4)$, as well as chronic conditions that require ongoing rehabilitation efforts such as COPD, CVD, diabetes, and obesity (3). Stroke telerehabilitation programs involving consultations, exercises, games, and therapy aspects have shown positive outcomes such as improving patients' functional abilities and mental health (4). Other benefits include increasing patient motivation and ease due to being in a home setting (73). It is important that patients receive enough support in areas such as technical setup and troubleshooting. The Telerehabilitation in Heart Failure Patients (TELEREH-HF) trial in Poland demonstrated that a 9-week hybrid comprehensive telerehabilitation (HCTR) program consisting of remote monitoring of training at patients' homes was well-tolerated $(24,25)$. However, the positive effects of the intervention didn't translate into improvement in clinical outcomes over a follow-up period of 12-24 months in comparison to standard care (24).

A 2018 systematic review similarly found that telerehabilitation allowed for equal or more significant patient outcomes than center-based rehabilitation programs in stroke (74). Furthermore, wearable devices can be used in the rehabilitation of various neurological diseases such as stroke, PD, multiple sclerosis, and TBI. Inactivity is associated with various comorbidities and is often a result of chronic neurological disease or acute accident recovery. Remote monitoring through wearable devices can track activity, gait, and any falls throughout rehabilitation (75).

TBI can result in cognitive issues such as sleep disturbance, photophobia, memory, and behavioral changes (76). It is crucial that patients are not discharged without a follow-up plan. A neuropsychological test battery in the few years following moderate-to-severe brain injury and inpatient rehabilitation is vital to assess any cognitive decline and plateau. During COVID-19 times, it is necessary to move outpatient testing of this sort to remote delivery, wherever feasible and while 
maintaining efficacy. The Brief Test of Adult Cognition (BTACT) has been shown to be effective over the telephone in patients with TBI to assess cognitive state (77). Remote monitoring of physical activity by physiotherapists and patient consultation with neurologists can also be achieved through telemedicine. However, clear guidelines for rehabilitation management and evidence of efficacy through different delivery systems are lacking (78).

Pulmonary rehabilitation is essential for patients with chronic respiratory issues such as COPD and can be achieved through telehealth measures such as monitoring, consultation, and education (79). This is important in COPD, as potential exacerbations need to be monitored, and lower levels of rehabilitation access are associated with increased rates of hospitalization (79). Additionally, personal movement tracking devices involving accelerometers are helpful in tracking patient exercise, which is an essential area of pulmonary rehabilitation (80). Telehealth rehabilitation still faces major hurdles, however, such as cost-effectiveness, patient training, and the lack of regulatory frameworks surrounding personal health devices (80).

\section{TELEMEDICINE IN PALLIATIVE CARE}

According to the WHO, about 40 million people annually need palliative care, and only $14 \%$ of them receive it (81). The importance of primary healthcare in palliative care was highlighted by the first WHO global resolution on palliative care in 2014. The Project ECHO (Extension for Community Healthcare Outcomes), as one of the examples, shows the potential of telemedicine in the training of patients, their family members, and medical workers in palliative care $(82,83)$. The training of palliative care via telemedicine/telehealth for outpatients in primary care will increase the coverage and quality of both care and life for these patients. Telehealth, including mobile applications, plays a role in making patients more adherent to both pharmacological and non-pharmacological therapies; in remote monitoring of clinical parameters such as cardiovascular and respiratory system function; as well as in monitoring of diet and physical activity. Given the overload of respiratory diseases and the flu-like presentations in routine practice, telemedicine offers an alternative that is particularly relevant in the COVID-19 era.

\section{TELEMEDICINE/TELEHEALTH APPLICATION IN MENTAL HEALTH}

Mental health support to frontline health workers, patients, and carers will be crucial, as long isolation, lack of social interaction, as well as anxiety over one's own and others' health will take a toll on well-being $(2-4,84)$. Psychotherapy, psychiatry, and counseling are easily converted to a teleconference format through platforms (such as-but not limited to-Zoom ${ }^{\mathrm{TM}}$ and Skype ${ }^{\mathrm{TM}}$ ) and should be utilized by frontline health workers, patients, and carers where necessary (85). Anecdotal evidence also suggests that patients experiencing paranoid, anxiety, or post-traumatic stress disorders, who may be particularly affected by the COVID-19 climate (84), may feel more comfortable undergoing telepsychiatry over in-person psychiatry. Online delivery will further help to resolve issues such as lack of access to practitioners in rural settings and cultural and linguistic barriers (86). Furthermore, psychoeducation and mental well-being advice can be leveraged through smartphone apps and digital outreach programs (87). These services will become increasingly crucial in the pandemic setting, as physical isolation and frontline work pose both access issues and mental health stressors. The ethics of such teleservices needs to be ensured, with patient confidentiality, referral and billing practices, and physician eligibility being upheld (88). Psychiatrists, psychotherapists, and psychologists need to ensure that they are maintaining their own mental health during this time, with programs such as professional supervision being of help (4).

\section{TELEHEALTH/TELEMEDICINE FOR THE ELDERLY}

In 2018, nearly one-fifth of the European population was aged over 65 years old (89). An aging population has put significant pressure on public spending; therefore, telemedicine can improve the scale and efficiency of delivery and ongoing management of elderly patients. Elderly patients with mild cognitive impairment or dementia who might be at high risk of an acute condition should be identified using mobile technologies and telemedicine, and telemedicine solutions for the elderly should be easy to use and possibly automatic (4). This would avoid unnecessary burdens to public health facilities. Telemedicine can also be used to act as an interface of the local nursing care staff, carers, and patients with medical specialists. Elderly patients will benefit from remote allied health delivery. Patients who have had a recent surgery could be monitored at home or in nursing care facilities, preventing extended hospital stays. Elderly patients with diagnosed mental health conditions could also benefit from telemedicine. However, self-efficacy and digital literacy presumably have a significant impact on the uptake of telehealth among the elderly (90).

Recent data from the US confirm that the most vulnerable age group for COVID-19 is people over 65 years old, and the highest mortality is observed in those aged 85 and older (91). In Ontario, Canada (as well as in Italy and the US), 54\% of deaths related to COVID-19 occurred in retirement homes and long-term care $(92,93)$. Strict zero-visitation policies have had debilitating effects for some elderly patients, particularly those with dementia (4). Telemedicine has been utilized to connect family members with these patients to prevent further decline in mental status and provide comfort. This is useful, as family members have voiced concerns that physically distanced visits such as through windows may further confuse their loved ones.

Telehealth allows continual monitoring of vitals, physical examination, ongoing clinical management, and communication with patients. In elderly patients with limited accessibility, telemedicine could provide an alternative, easy-to-access service. Elderly patients often suffer from social isolation, and telehealth can bring a sense of community. Furthermore, by using AI, falls can be detected among elderly patients (94). AI can provide personalized medicine solutions to help identify patients at risk of 
harm. Primary healthcare physicians and nursing homes should watch for signs of depression in the elderly, particularly as it has been shown that telemedicine is competent in managing depressive symptoms in the elderly (95).

\section{TELEHEALTH/TELEMEDICINE FOR CONGREGATE SETTINGS}

Telemedicine can be useful in delivering interventions in congregate settings $(96,97)$. Challenges in congregate settings include high population density, limited mobility, built environment issues, and limited access to health. This can make the prevention and management of COVID-19 onerous while preserving human rights and ethical issues. Some of the potential target populations include refugees and migrants (96), those living in incarceration, orphanages, old-age homes, or childcare centers; and schools. These populations are especially vulnerable to infection such as COVID-19, where an outbreak can have facility-wide implications and adverse health consequences and fatality. A simulation study on the possible impact of COVID-19 outbreak in a Bangladeshi refugee camp found a dire need for dramatic increases in healthcare capacity and infrastructure (97). Existing approaches to control an outbreak, should it occur, would not be practically feasible, necessitating innovative solutions as well as novel and untested strategies in humanitarian settings (97). Telepsychiatry to monitor and deliver interventions in congregate settings, especially among refugee populations living in resource-constrained areas $(98,99)$, could be an alternative when traditional therapy is not possible. Telepsychiatry programs for congregate settings should be developed, and further studies are needed to evaluate their long-term impact on patient monitoring and care $(99,100)$.

\section{COST-BENEFIT ANALYSIS}

Telemedicine systems are not novel concepts and have been used to good effect for programs such as forward triage in EDs, critical care monitoring, and physician communication. Existing systems will need to be reallocated, and innovations will be pushed through in order to provide care across all medical fields and to reduce hospital burden. This needs to be achieved within the constraints of funding, legislation, and supply-chain barriers. Temporary government funding will be necessary to roll out telemedicine to both rural and urban settings, as well as relaxations to legislation that allow practitioner reimbursement of telemedicine services (101). A study by Sayani et al., addressing the cost and time barriers in chronic disease management through telemedicine in LMICs, found telemedicine to be economically beneficial not only by reducing the socioeconomic barriers to cost and access but also by increasing the uptake of services (102). Another systematic review of studies conducted on costs of home-based telemedicine programs from 2000 to 2017 found that home telemedicine programs reduced care costs, although detailed cost data were either incomplete or not presented in detail (103). The data on the cost-effectiveness of telemedicine solutions in different medical areas remains inconsistent and confounded by many variables, including the type of disease and "digital maturity" of healthcare systems. However, in critical situations such as the COVID-19 pandemic, telemedicine is proven necessary, and costing, billing, and reimbursement solutions are needed.

\section{REIMBURSEMENT OF ALL TELEHEALTH PROVIDERS}

There are variations in reimbursement policies across regions and healthcare systems. One of the major barriers has been harmonizing a standard reimbursement policy that is acceptable to all stakeholders and sustainable. We recommend that an integrated framework involving public and private parties could help develop a less complicated and streamlined reimbursement structure. Notably, the adoption of a "flip the switch" health insurance strategy in North Carolina to reimburse telehealth visits "at parity" with conventional office visits for all healthcare providers and specialists is timely and essential. In the long term, the impact of these strategies on healthcare quality and healthcare costs needs further study. Healthcare providers must lead the way here in the COVID-19 crisis to explore innovative approaches such as $\mathrm{B} 2 \mathrm{~B}$ monitoring.

\section{LIMITATIONS OF TELEMEDICINE}

Certain limitations may act as roadblocks in the uptake, implementation, and scale-up of telemedicine and supporting technologies. Considerable training is required to ensure patients can familiarize themselves with video teleconsultations and the use of supportive technologies. Physicians also need targeted technical, clinical, and communication training based on their subspecialty needs. Issues of limited access to broadband and Internet facilities are an area that particularly limits the deployment of telemedicine in remote areas and under-resourced settings. Telehealth requires reliable broadband access, which is not always acceptable both for clinics in rural areas and for patients living in such areas. When using telemedicine technology, legal restrictions and a lack of clarity as to what is permitted are possible, and these restrictions force telemedicine providers to proceed with caution. Some conditions are not considered in the legislation of health systems. It is still not entirely clear whether virtual consultations and video surveillance will be fully paid in hospitals or will be evaluated as shorter visits so that the rates will be lowered. Physician licensing and stability of the telemedicine infrastructures are issues of relevance in under-resourced settings.

Several critical medical procedures cannot be replaced by telemedicine, nor can it be offered to everyone, and there are many excluded groups of patients, including those with deficiencies (e.g., deaf and blind patients) and elderly patients. The effectiveness of telemedicine relies on the possibilities of the implementation of these tools in the given hospital/healthcare system, preparations/training of physicians/nurses, and awareness of the patients. 
TABLE 1 | Telemedicine across various medical subspecialties.

\begin{tabular}{|c|c|c|}
\hline & Telemedicine studies & Outcome parameter \\
\hline \multirow{2}{*}{$\begin{array}{l}\text { Telemedicine in emergency cases and } \\
\text { triage }\end{array}$} & Brennan et al. (104) & Reduced average patient throughput time (from admission to discharge). \\
\hline & Dharmar et al. (105) & Improved physician-rated quality of care. \\
\hline \multirow[t]{4}{*}{ Telecardiology } & Molinari et al. (106) & Reduced hospitalizations in patients with suspected life-threatening cardiac events. \\
\hline & Khader et al. (107) & Improvement in the quality of life 2 months after the first visit. \\
\hline & Scalvini et al. (108) & $\begin{array}{l}\text { Possible cost reduction due to increased appropriateness of hospital admission and } \\
\text { of diagnostic testing. }\end{array}$ \\
\hline & Sable et al. (109) & $\begin{array}{l}\text { Positive impact on referral patterns and time management in pediatric cardiology } \\
\text { practice without increasing the utilization of echocardiography. }\end{array}$ \\
\hline \multirow[t]{2}{*}{ Teleneurology } & Capozzo et al. (110) & $\begin{array}{l}\text { Feasible to triage amyotrophic lateral sclerosis (ALS) patients using telemedicine. } \\
\text { Increase in practice outreach and efficiency, especially in COVID-19 times. }\end{array}$ \\
\hline & Ohta et al. (111) & $\begin{array}{l}\text { Significant improvement in the state and trait anxiety inventories (STAl) scores in } \\
\text { Parkinson's disease (PD), ALS, and spinocerebellar degeneration (SCD) + multiple } \\
\text { system atrophy (MSA) patients. }\end{array}$ \\
\hline \multirow[t]{5}{*}{ Tele-acute neurology } & Medeiros de Bustos et al. (112) & Reduction in secondary interhospital transfers. \\
\hline & Vatankhah et al. (113) & Immediate impact on clinical decisions. \\
\hline & Lyerly et al. (114) & Telemedicine increased access to acute stroke care. \\
\hline & Dharmasaroja et al. (115) & $\begin{array}{l}\text { Telemedicine increased intravenous thrombolysis rates without compromising } \\
\text { favorable and safety outcomes. }\end{array}$ \\
\hline & Schwab et al. (116) & $\begin{array}{l}\text { Comparable mortality rates and functional outcomes for telemedicine-linked } \\
\text { community hospitals and stroke centers to the results from randomized trials. }\end{array}$ \\
\hline \multirow[t]{2}{*}{$\begin{array}{l}\text { Telemedicine in critical care and } \\
\text { respiratory management }\end{array}$} & Yang et al. (117) & $\begin{array}{l}\text { Telemedicine feasible to support acute management of children who present to } \\
\text { community hospitals. }\end{array}$ \\
\hline & Kuipers et al. (118) & $\begin{array}{l}\text { Acceptable positive predictive value of the electronic inhalation monitoring devices } \\
\text { (EIMDs) in patients with respiratory diseases. }\end{array}$ \\
\hline \multirow[t]{4}{*}{ Chronic disease and primary care } & Orozco-Beltran et al. (119) & $\begin{array}{l}\text { Telemonitoring program effective in reducing high risk for rehospitalization or an } \\
\text { emergency department visit. }\end{array}$ \\
\hline & Doñate-Martínez et al. (120) & $\begin{array}{l}\text { Telemedicine program improved self-reported quality of life and decreased use of } \\
\text { health resources in elderly patients with chronic diseases. High satisfaction levels also } \\
\text { observed in patients on the program. }\end{array}$ \\
\hline & Martín-Lesende et al. (121) & $\begin{array}{l}\text { Telemonitoring of in-home patients with heart failure and/or chronic lung disease led } \\
\text { to an increase in the percentage of patients with no hospital admissions. Trend } \\
\text { toward reduced total and cause-specific hospitalizations and hospital stay. }\end{array}$ \\
\hline & Palmieri et al. (122) & $\begin{array}{l}\text { No significant impact of home-based telemonitoring program on all-cause } \\
\text { hospitalization/mortality. Telemonitoring associated with higher patient compliance } \\
\text { and achievement of therapeutic targets. }\end{array}$ \\
\hline \multirow[t]{2}{*}{$\begin{array}{l}\text { Identifying those with bulbar and } \\
\text { respiratory weakness }\end{array}$} & Pinto et al. (123) & $\begin{array}{l}\text { Home-based telemonitoring of non-invasive ventilation decreased healthcare } \\
\text { utilization in patients with ALS. }\end{array}$ \\
\hline & Paganoni et al. (124) & $\begin{array}{l}\text { Video visits associated with marked adjusted cost savings for patients and } \\
\text { institutions. }\end{array}$ \\
\hline $\begin{array}{l}\text { Telemedicine-assisted follow-up and } \\
\text { rehabilitation }\end{array}$ & Rawstorn et al. (125) & $\begin{array}{l}\text { Telehealth exercise-based cardiac rehabilitation is as effective as center-based } \\
\text { rehabilitation for improving modifiable cardiovascular risk factors and functional } \\
\text { capacity. } \\
\text { Note: Systematic review included } 11 \text { clinical trials. }\end{array}$ \\
\hline \multirow[t]{2}{*}{ Telemedicine in palliative care } & Kuntz et al. (126) & $\begin{array}{l}\text { Electronic family (e-family) meetings to facilitate in-patient palliative care during } \\
\text { coronavirus disease } 2019 \text { (COVID-19) pandemic feasible and well received by } \\
\text { families. }\end{array}$ \\
\hline & Nemecek et al. (127) & $\begin{array}{l}\text { Telemedicine augmented palliative care feasible in patients with advanced care and } \\
\text { their family carers. Significant reduction in anxiety levels in the telemedicine group vs. } \\
\text { the standard care. }\end{array}$ \\
\hline \multirow[t]{4}{*}{ Telemedicine in mental health } & Ruskin et al. (128) & $\begin{array}{l}\text { Telepsychiatry and in-person treatment of depression have comparable outcomes. } \\
\text { Equivalent levels of patient adherence, patient satisfaction, and healthcare cost. }\end{array}$ \\
\hline & Salisbury et al. (129) & $\begin{array}{l}\text { Telehealth service leveraging non-clinically-trained health advisers supporting patients } \\
\text { in use of Internet resources was both acceptable and effective compared with usual } \\
\text { care. }\end{array}$ \\
\hline & O’Reilly et al. (128) & Clinical outcomes of telepsychiatry equivalent to standard of care. \\
\hline & Chipps et al. (99) & Telepsychiatry programs are feasible in congregate settings. \\
\hline
\end{tabular}



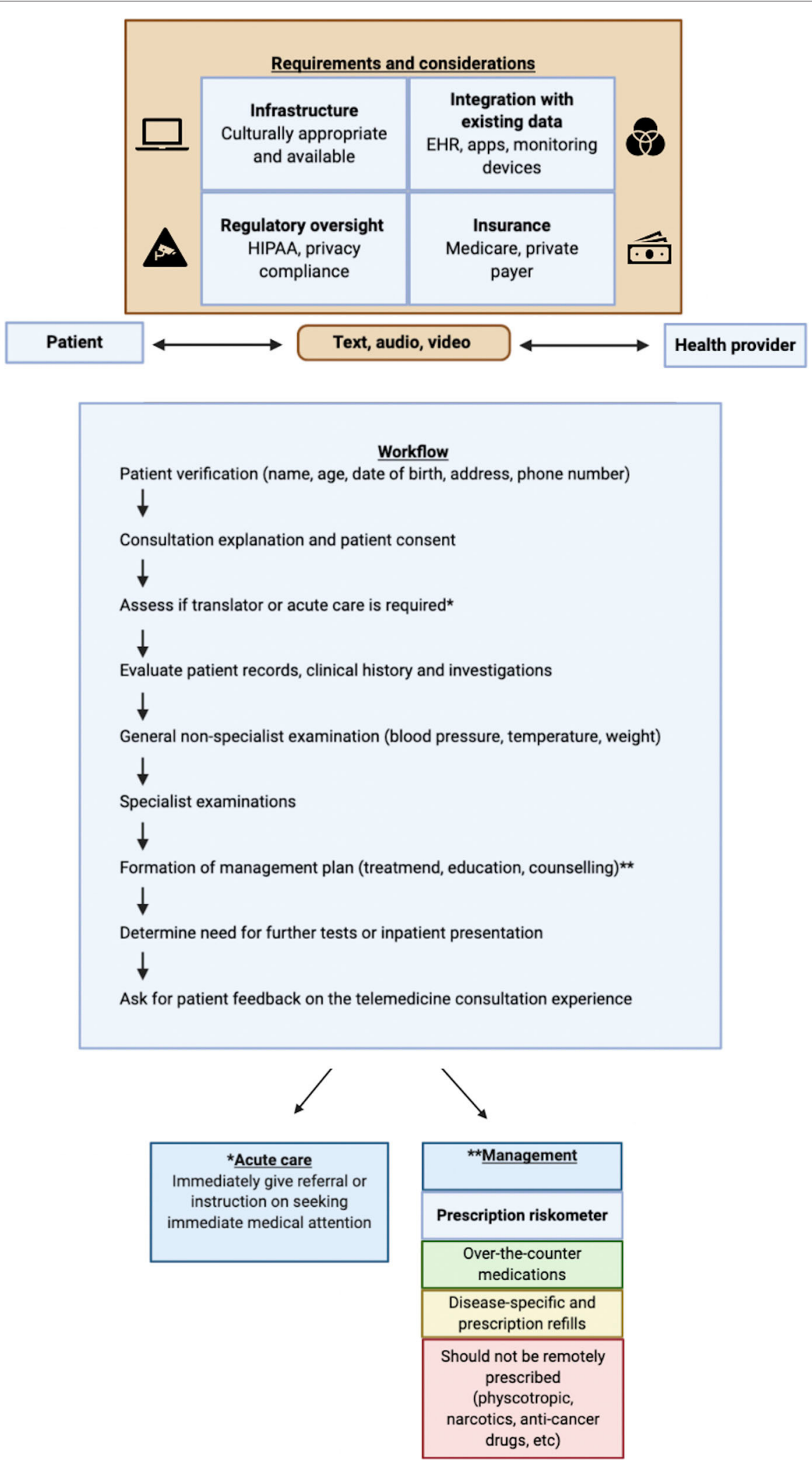

FIGURE 1 | Various requirements and considerations for streamlined telemedicine implementation and the Pandemic Health System REsilience PROGRAM (REPROGRAM) consortium workflow for routine teleconsultation and management of patients. Patients and healthcare providers can interact through telemedicine via 
FIGURE 1 | text, audio, or video means. Effective telemedicine has several requirements, including culturally appropriate and available infrastructure; regulatory oversight and privacy compliance such as through the Health Insurance Portability and Accountability Act of 1996 (HIPAA); integration of technologies with existing data such as electronic health records (EHRs), apps, and monitoring devices; and insurance coverage such as Medicare or private-payer schemes. Credentialing on both sides is essential. The consultation should start with verification of the patient's identity through name, age, phone number, date of birth, and address. The physician should then clearly specify that this is a telemedicine consult and that no audio or video of the communication will be recorded. It is imperative that health record information is protected. The physician should then clearly and explicitly ask for consent, whether that be verbal, text, or video. At the start of the consultation, the physician should assess if acute care is required and make a cursory determination if telemedicine consultation is sufficient. If necessary, the physician should supply an immediate referral or advise the patient to seek immediate medical attention. During a typical consultation, the patient will be evaluated; and specific diagnostics and treatment would be recommended based on the assessment of the healthcare provider; and follow-up could be scheduled either in person or virtually. The physician should go through records, clinical history, and investigations including pathology and diagnostic reports, and obtain any additional information that the patient can provide. A general, non-specialist examination should be obtained, and any vital signs that the patient has the means to measure should be gathered.

Beyond this, when introducing technologies and measures to overcome gaps in the healthcare system, it is essential not to simply ask, "where are the gaps," but also to define the standards and ideals of care and continually iterate toward these ideals. As mentioned before, telemedical consultations do not approach the same level of fidelity that an in-person physical exam yields, between physical exams, body language, vocal intonations, and odors. As such, the fidelity of the technology involved with telemedical consults must continually iterate to reach the same level of fidelity and information that an inperson visit might yield. In this vein, virtual and augmented reality technologies, while evolving, hold promise for the future of telemedicine, particularly in envisioning a future in which high-fidelity physician and patient "avatars" may meet in a virtual space for a telemedical consult, replicating aspects of an inperson visit through immersive technologies.

\section{CONCLUSION AND FUTURE DISCUSSION}

COVID-19 has expedited the uptake of telemedicine across various specialties. The rapid move by various bodies, associations, and providers to use telemedicine in maintaining patient continuity while limiting COVID-19 risks of exposure to patients and healthcare workers will have a long-term impact well-beyond the current pandemic. Teleconsultation needs are varied across specialties, and therefore, specialty-specific guidelines and recommendations need to be developed. A scoping list of various telemedicine studies across medical subspecialties (telemedicine vs. standard care) has been provided in Table 1. A comprehensive workflow that critically profiles various telemedicine enablers has been proposed in Figure 1, and recommendations to improve various factors are listed in Table 2.

The proposed workflow (Figure 1) provides a practical telemedicine framework cognizant of relevant requirements and considerations, and a step-by-step pathway to streamlined telemedicine delivery. This could be used as a template (for further customization or adaptation) by individual medical subspecialties. Current challenges and recommendations to improve telemedicine include (130): (i) infrastructure capacity [formation and expansion of dedicated telemedicine units and workforce; cloud-based infrastructure to support telemedicine associated bandwidth traffic; liability, maintenance, and safety of telemedicine platforms; ongoing and regular maintenance and servicing of telemedicine hardware and software; awareness, education, and training to build confidence about telemedicine use among providers and consumers; compulsory telemedicine modules for medical students and continued professional development (CPD) workshops/courses for healthcare providers and medical informaticians/technologists; targeted courses aimed at re-skilling clinicians]; (ii) integration with existing data (standardized patient-specific information and consent form with telemedicine opt-in/out option); (iii) regulatory oversight issues (setup of telemedicine regulatory authority; accreditation/licensing of providers using telemedicine; guidelines for telemedicine use in inter-state and -nation settings; standardization of telemedicine related technologies and services with regulatory oversight, audit, and reporting; appropriate measures and oversight to protect privacy, security, and confidentiality of patient data; legal frameworks for telemedicine-specific information storage, sharing, and access); and (iv) insurance/payers (guidelines for telemedicine insurance; streamlined payment facilities for making and receiving payments; bundled services payments and insurance coverage).

Another important and emerging area is the use of text messaging [short message service (SMS) or multimedia message service (MMS)] as a model for service delivery (131-136). Text messaging has proven efficacious in diabetes self-management, smoking cessation, weight loss, physical activity, and adherence to medication regimens [such as in human immunodeficiency virus infection and acquired immune deficiency syndrome (HIV/AIDS) patients who are on antiretroviral therapy] (132). A systematic review on text messaging interventions identified the following issues: identification of intervention characteristics, ensuring intervention effects last over a longer duration of time, and cost-effectiveness of these interventions (132). Issues of privacy and security are also poignant in this context. Nevertheless, text messaging offers potential benefit as a public health intervention toward chronic disease management (133136), medication adherence, and secondary prevention (134).

Perceptions and experiences/satisfaction, regarding telemedicine services, of the patients and providers is important in improving telemedicine implementation, delivery, and impact (137-141). A systematic review on patient satisfaction with telemedicine highlighted methodological deficiencies in published studies (137). A study on patient and clinician experience with telemedicine found that virtual video visits may provide effective follow-up and increased convenience in comparison to routine in-person visits (139). Another study found a perception of patients with type 2 diabetes that 
TABLE 2 | Various factors in telemedicine implementation and corresponding recommendations from the consortium.

\begin{tabular}{ll}
\hline Factors & Recommendations \\
\hline Physician licensing & $\begin{array}{l}\text { Facilitation and harmonization of inter-state } \\
\text { licensing. Specialty-specific considerations for } \\
\text { telemedicine-based care. }\end{array}$ \\
Bandwidth and infrastructure & Mobile phone-based Internet to avail of \\
& telemedicine, mobile Wi-Fi routers. The \\
& concerted effort through a public-private \\
& partnership involving key corporate players to \\
& improve Internet penetration in these pockets. \\
& Need domain experts to ensure that \\
& technologies are appropriately deployed. \\
& Medicare-for-all coverage. The government \\
needs to provide funding to develop platforms & with minimal expenditure. \\
availability & Specialty-specific training for clinicians and \\
Clinician uptake & for easy and improved access. \\
Quality control, regular re-skilling of & professionals involved, ensuring infrastructure \\
is being monitored. Collaboration between \\
various stakeholders, including providers and \\
insurance payers.
\end{tabular}

Language barriers

Privacy

User training and technology deployment/access to hardware

Liability

Geographical limitations

Under-resourced settings

Complex cases

Patient-doctor relationship
Technologies such as mobile apps that can be easily incorporated into telemedicine workflow.

Blockchain-based platforms or applications could safeguard the privacy of physicians.

Appropriate training addressing bias and nuances toward adopting telemedicine. Funding support and rapid deployment of telemedicine technologies across all providers. Provision for delivery of "bundled" telemedicine act as enablers. Performance evaluation, ongoing assessment of patient and provider experiences, and adapting to address gaps.

Developing clear-cut guidelines to mitigate communication and technology-specific risks and liability. This should be done in consultation with providers, patients, and insurance/payers.

Use of low-bandwidth applications. Change management and culture-specific support.

Technology-based health promotion, leveraging mobile health applications for community outreach, healthcare buddies who liaise with the community to educate and inform about technology and use. The WHO needs to take the lead in ensuring penetration of telemedicine in under-resourced locations in collaboration with philanthropic partners.

Evidence-based guidelines and workflow recommendations. Various boards, associations, and bodies should formalize standard protocols that could clearly delineate dos and don'ts of clinical examination, diagnosis, and management using telemedicine technologies.

Communication tool kit or handouts to improve user experience. Privacy and communication to patients that clinical data and consultations would remain confidential is critical. services. Public and private partnerships can telemedicine can improve their access to care (140). Further studies focusing on communication issues and the quality of interpersonal relationships during telemedicine consultations and how these factors affect healthcare delivery using this medium are required $(137,141)$.

Some specialist examinations, including neurologist consultation, can also be conducted. The American Academy of Neurology has issued guidelines for telemedicine consultation (142). Physicians can assess mental status; any visual, auditory, or cognitive deficits; comprehensive speech; cranial nerves; apparent tremors; and gait. Motor examinations can also be conducted with the aid of a caregiver in order to help ascertain strength, tone, reflexes, dermatome sensation, and cerebellar function. In such a case, consent must be gained from both the patient and the assistor. Special considerations may apply for pediatric patients or adults with intellectual disabilities. Based on the severity of symptoms, the patient may require a management plan, including specific treatment, health education, and counseling if necessary. Patients can be prescribed ongoing prescriptions, specific medications, or add-on medication to optimize regimes, given that there is no ambiguity about diagnosis and the medications are not dangerous. If there is any ambiguity about diagnosis, this must be recognized as a limitation of this mode of telemedicine, and documentation must be made. Further tests should be done or referred for in-person consultation if necessary. It should be noted that detailed examination of tone, strength, and reflexes; comprehensive eye examinations; and examinations that require specific maneuvers such as vestibular examinations should be avoided, as examination findings won't be accurate. These recommendations will also need to be adjusted according to individual state or federal legislation. The future of telemedicine beyond the current COVID-19 pandemic will depend on how we address existing challenges, building resilient health systems $(2-4)$. Further randomized controlled trials to evaluate the long-term effects of telemedicine-based interventions in various patient populations should be planned. Telemedicine will play a major role as a "safety net" during the pandemic.

\section{AUTHOR'S NOTE}

The COVID-19 pandemic is causing an unprecedented public health crisis impacting healthcare systems, healthcare workers, and communities. The COVID-19 Pandemic Health System REsilience PROGRAM (REPROGRAM) consortium is formed to champion the safety of healthcare workers, policy development, and advocacy for global pandemic preparedness and action.

\section{AUTHOR CONTRIBUTIONS}

SBh devised the project, the main conceptual ideas, including the proposal for a new telemedicine workflow, the proof outline, and coordinated the writing and editing of the manuscript. SBh and $\mathrm{SBr}$ wrote the first draft of the manuscript. SBh encouraged SBr to 
investigate and supervised the findings of this work. All authors discussed the results and recommendations and contributed to the final manuscript.

\section{ACKNOWLEDGMENTS}

We would like to acknowledge the REPROGRAM consortium members, who have worked tirelessly over the last days in

\section{REFERENCES}

1. Klompas M. Coronavirus disease 2019 (COVID-19): protecting hospitals from the invisible. Ann Int Med. (2020) 172:619-20. doi: 10.7326/M20-0751

2. Bhaskar S, Sharma D, Walker AH, McDonald M, Huasen B, Haridas A, et al. Acute neurological care in the COVID-19 era: the pandemic health system REsilience PROGRAM (REPROGRAM) consortium pathway. Front Neurol. (2020) 11:579. doi: 10.3389/fneur.2020.00579

3. Bhaskar S, Rastogi A, Chattu VK, Adisesh A, Thomas P, Alvarado $\mathrm{N}$, et al. Key Strategies for clinical management and improvement of healthcare services for cardiovascular disease and diabetes patients in the coronavirus (COVID-19) settings: recommendations from the REPROGRAM consortium. Front Cardiovasc Med. (2020) 7:112. doi: $10.3389 /$ fcvm.2020.00112

4. Bhaskar S, Bradley S, Israeli-Korn S, Menon B, Chattu VK, Thomas P, et al. Chronic neurology in COVID-19 era: clinical considerations and recommendations from the REPROGRAM consortium. Front Neurol. (2020) 11:664. doi: 10.3389/fneur.2020.00664

5. American Telemedicine Association. About Telemedicine. Available online at: http://legacy.americantelemed.org/main/about/about-telemedicine/ telemedicine-faqs (accessed April 16, 2020).

6. World Health Organization (WHO). Artificial Intelligence for Good Global Summit. Director Generals'. (2018). Available online at: https://www.who. int/dg/speeches/2018/artificial-intelligence-summit/en/ (accessed April 12, 2020).

7. Siwicki B. Telemedicine during COVID-19: Benefits, limitations, burdens, adaptation. Healthcare IT News. Available online at: https://www. healthcareitnews.com/news/telemedicine-during-covid-19-benefitslimitations-burdens-adaptation (accessed April 16, 2020).

8. Zimetbaum P, Goldman A. Ambulatory arrhythmia monitoring. Circulation. (2010) 122:1629-36. doi: 10.1161/CIRCULATIONAHA.109.925610

9. Napi NM, Zaidan AA, Zaidan BB, Albahri OS, Alsalem MA, Albahri AS. Medical emergency triage and patient prioritisation in a telemedicine environment: a systematic review. Health Technol. (2019) 9:679-700. doi: 10.1007/s12553-019-00357-w

10. Sharma R, Fleischut P, Barchi D. Telemedicine and its transformation of emergency care: a case study of one of the largest US integrated healthcare delivery systems. Int J Emerg Med. (2017) 10:21. doi: 10.1186/s12245-017-0146-7

11. Fried JA, Ramasubbu K, Bhatt R, Topkara VK, Clerkin KJ, Horn E, et al. The variety of cardiovascular presentations of COVID-19. Circulation. (2020) 141:1930-6. doi: 10.1161/CIRCULATIONAHA.120.047164

12. Shi S, Qin M, Shen B, Cai Y, Liu T, Yang F, et al. Association of cardiac injury with mortality in hospitalized patients with COVID-19 in Wuhan, China. JAMA Cardiol. (2020) 5:802-10. doi: 10.1001/jamacardio.2020.0950

13. Inciardi RM, Lupi L, Zaccone G, Italia L, Raffo M, Tomasoni D, et al. Cardiac involvement in a patient with coronavirus disease 2019 (COVID-19). JAMA Cardiol. (2020) 5:819-24. doi: 10.1001/jamacardio.2020.1096

14. Guo T, Fan Y, Chen M, Wu X, Zhang L, He T, et al. Cardiovascular implications of fatal outcomes of patients with coronavirus disease 2019 (COVID-19). JAMA Cardiol. (2020) 5:811-8. doi: 10.1001/jamacardio.2020.1017

15. Bonow RO, Fonarow GC, O'Gara PT, Yancy CW. Association of coronavirus disease 2019 (COVID-19) with myocardial injury and mortality. JAMA Cardiol. (2020). doi: 10.1001/jamacardio.2020.1105. [Epub ahead of print]. contributing to various guidelines, recommendations, policy briefs, and ongoing discussions during these unprecedented and challenging times despite the incredibly short timeframe. We would like to dedicate this work to our healthcare workers who have died due to COVID-19 while serving patients at the frontline and to those who continue to serve during these challenging times despite the lack of personal protective equipment.

16. Bhatt A, Freeman A, Mullen B. Telehealth: Rapid Implementation for Your Cardiology Clinic. Available online at: https://www.acc.org/ latest-in-cardiology/articles/2020/03/01/08/42/feature-telehealth-rapidimplementation-for-your-cardiology-clinic-coronavirus-disease-2019covid-19 (accessed April 16, 2020).

17. Linschoten, Asselbergs FW. CAPACITY-COVID: a European Registry to determine the role of cardiovascular disease in the COVID-19 pandemic. Eur Heart J. (2020) 41:1795-6. doi: 10.1093/eurheartj/ehaa280

18. Kuehn BM. Telemedicine helps cardiologists extend their reach. Circulation. (2016) 134:1189-91. doi: 10.1161/CIRCULATIONAHA.116.025282

19. Inglis SC, Clark RA, Dierckx R, Prieto-Merino D, Cleland JG. Structured telephone support or non-invasive telemonitoring for patients with heart failure. Cochrane Database Syst Rev. (2015) Cd007228. doi: 10.1002/14651858.CD007228.pub3

20. Brunetti ND, Molinari G, Acquistapace F, Zimotti T, Parati G, Indolfi C, et al. 2019 Italian Society of Cardiology Census on telemedicine in cardiovascular disease: a report from the working group on telecardiology and informatics. Open Heart. (2020) 7:e001157. doi: 10.1136/openhrt-2019-001157

21. Satou GM, Rheuban K, Alverson D, Lewin M, Mahnke C, Marcin $\mathrm{J}$, et al. Telemedicine in pediatric cardiology: a scientific statement from the American Heart Association. Circulation. (2017) 135:e648-78. doi: 10.1161/CIR.0000000000000478

22. Gandapur Y, Kianoush S, Kelli HM, Misra S, Urrea B, Blaha MJ, et al. The role of mHealth for improving medication adherence in patients with cardiovascular disease: a systematic review. Eur Heart J Qual Care Clin Outcomes. (2016) 2:237-44. doi: 10.1093/ehjqcco/qcw018

23. Honeyman E, Ding H, Varnfield M, Karunanithi M. Mobile health applications in cardiac care. Int Cardiol. (2014) 6:227-40. doi: $10.2217 /$ ica. 14.4

24. Piotrowicz E, Pencina MJ, Opolski G, Zareba W, Banach M, Kowalik I, et al. Effects of a 9-week hybrid comprehensive telerehabilitation program on long-term outcomes in patients with heart failure: the telerehabilitation in heart failure patients (TELEREH-HF) randomized clinical trial. JAMA Cardiol. (2020) 5:300-8. doi: 10.1001/jamacardio.2019.5006

25. Piotrowicz E, Piotrowicz R, Opolski G, Pencina M, Banach M, Zareba W. Hybrid comprehensive telerehabilitation in heart failure patients (TELEREH-HF): a randomized, multicenter, prospective, open-label, parallel group controlled trial-Study design and description of the intervention. Am Heart J. (2019) 217:148-58. doi: 10.1016/j.ahj.2019.08.015

26. Moustafa H, Barlinn K, Prakapenia A, Winzer S, Gerber J, Pallesen LP, et al. Endovascular therapy for anterior circulation large vessel occlusion in telestroke. J Telemed Telecare. (2019) 1357633x19867193. doi: 10.1177/1357633x19867193

27. Gabriel KMA, Jíru-Hillmann S, Kraft P, Selig U, Rücker V, Mühler J, et al. Two years' experience of implementing a comprehensive telemedical stroke network comprising in mainly rural region: the Transregional Network for Stroke Intervention with Telemedicine (TRANSIT-Stroke). BMC Neurol. (2020) 20:104. doi: 10.1186/s12883-020-01676-6

28. Chaffin HM, Nakagawa K, Koenig MA. Impact of Statewide Telestroke Network on acute stroke treatment in Hawai'i. Hawaii J Health Soc Welf. (2019) 78:280-6.

29. Cheshire WP, Barrett KM, Eidelman BH, Mauricio EA, Huang JF, Freeman WD, et al. Patient perception of physician empathy in stroke telemedicine. J Telemed Telecare. (2020) 1357633x19899237. doi: $10.1177 / 1357633 \times 19899237$ 
30. Swanson MB, Miller AC, Ward MM, Ullrich F, Merchant KAS, Mohr NM. Emergency department telemedicine consults decrease time to interpret computed tomography of the head in a multi-network cohort. J Telemed Telecare. (2019) 1357633X19877746. doi: 10.1177/1357633X19877746

31. Calderon VJ, Kasturiarachi BM, Lin E, Bansal V, Zaidat OO. Review of the mobile stroke unit experience worldwide. Interv Neurol. (2018) 7:347-58. doi: 10.1159/0004 87334

32. Yue JK, Upadhyayula PS, Avalos LN, Phelps RRL, Suen CG, Cage TA. Concussion and mild-traumatic brain injury in rural settings: epidemiology and specific health care considerations. J Neurosci Rural Pract. (2020) 11:2333. doi: 10.1055/s-0039-3402581

33. Barker-Davies RM, O'Sullivan O, Senaratne KPP, Baker P, Cranley M, Dharm-Datta S, et al. The Stanford Hall consensus statement for post-COVID-19 rehabilitation. Br J Sports Med. (2020) 54:949-59. doi: 10.1136/bjsports-2020-102596

34. Subramanian S, Pamplin JC, Hravnak M, Hielsberg C, Riker R, Rincon F, et al. Tele-critical care: an update from the society of critical care medicine tele-ICU committee. Crit Care Med. (2020) 48:553-61. doi: 10.1097/CCM.0000000000004190

35. Wilcox ME, Adhikari NK. The effect of telemedicine in critically ill patients: systematic review and meta-analysis. Crit Care. (2012) 16:R127. doi: $10.1186 / \mathrm{cc} 11429$

36. Ambrosino N, Makhabah DN, Sutanto YS. Tele-medicine in respiratory diseases. Multidisc Respir Med. (2017) 12:9. doi: 10.4081/mrm.2017.232

37. Ambrosino N, Vagheggini G, Mazzoleni S, Vitacca M. Telemedicine in chronic obstructive pulmonary disease. Breathe. (2016) 12:350. doi: $10.1183 / 20734735.014616$

38. Flodgren G, Rachas A, Farmer A, Inzitari M, Shepperd S. Interactive telemedicine: effects on professional practice and health care outcomes. Cochr Database Syst Rev. (2015) 9:CD002098. doi: 10.1002/14651858.CD002098.pub2

39. Katsiki N, Banach M, Mikhailidis DP. Lipid-lowering therapy and reninangiotensin-aldosterone system inhibitors in the era of the COVID-19 pandemic. Arch Med Sci. (2020) 16:485-9. doi: 10.5114/aoms.2020.94503

40. Tande AJ, Berbari EF, Ramar P, Ponamgi SP, Sharma U, Philpot L, et al. Association of a remotely offered infectious diseases eConsult service with improved clinical outcomes. Open Forum Infect Dis. (2020) 7:ofaa003. doi: 10.1093/ofid/ofaa003

41. Helleman J, Kruitwagen ET, van den Berg LH, Visser-Meily JMA, Beelen A. The current use of telehealth in ALS care and the barriers to and facilitators of implementation: a systematic review. Amyotroph Lateral Scler Frontotemporal Degener. (2020) 21:167-82. doi: 10.1080/21678421.2019.1706581

42. Helleman J, Van Eenennaam R, Kruitwagen ET, Kruithof WJ, Slappendel MJ, Van Den Berg LH, et al. Telehealth as part of specialized ALS care: feasibility and user experiences with "ALS home-monitoring and coaching”. Amyotroph Lateral Scler Frontotemporal Degener. (2020) 21:18392. doi: 10.1080/21678421.2020.1718712

43. Klein BC, Busis NA. COVID-19 is catalyzing the adoption of teleneurology. Neurology. (2020) 94:903-4. doi: 10.1212/WNL.0000000000009494

44. Achey M, Aldred JL, Aljehani N, Bloem BR, Biglan KM, Chan P, et al. The past, present, and future of telemedicine for Parkinson's disease. Mov Disord. (2014) 29:871-83. doi: 10.1002/mds.25903

45. Katz M. Telehealth increases access to palliative care for people with Parkinson's disease and related disorders. Ann Palliat Med. (2020) 9(Suppl. 1):S75-9. doi: 10.21037/apm.2019.11.12

46. Banach M, Penson PE, Fras Z, Vrablik M, Pella D, Reiner Ž, et al. Brief recommendations on the management of adult patients with familial hypercholesterolemia during the COVID-19 pandemic. Pharmacol Res. (2020) 158:104891. doi: 10.1016/j.phrs.2020.104891

47. Szperka CL, Ailani J, Barmherzig R, Klein BC, Minen MT, Halker Singh $\mathrm{RB}$, et al. Migraine care in the era of COVID-19: clinical pearls and plea to insurers. Headache. (2020) 60:833-42. doi: 10.1111/head.13810

48. Yeoh CB, Lee KJ, Rieth EF, Mapes R, Tchoudovskaia AV, Fischer GW, et al. COVID-19 in the cancer patient. Anesth Anal. (2020) 131:16-23. doi: 10.1213/ANE.0000000000004884
49. Weinkove R, McQuilten ZK, Adler J, Agar MR, Blyth E, Cheng AC, et al. Managing haematology and oncology patients during the COVID19 pandemic: interim consensus guidance. Med J Aust. (2020) 212:481-9. doi: $10.5694 / \mathrm{mja} 2.50607$

50. Xia Y, Jin R, Zhao J, Li W, Shen H. Risk of COVID-19 for patients with cancer. Lancet Oncol. (2020) 21:e180. doi: 10.1016/S1470-2045(20)30150-9

51. Lambertini M, Toss A, Passaro A, Criscitiello C, Cremolini C, Cardone C, et al. Cancer care during the spread of coronavirus disease 2019 (COVID19) in Italy: young oncologists' perspective. ESMO Open. (2020) 5:e000759. doi: 10.1136/esmoopen-2020-000759

52. Liang W, Guan W, Chen R, Wang W, Li J, Xu K, et al. Cancer patients in SARS-CoV-2 infection: a nationwide analysis in China. Lancet Oncol. (2020) 21:335-7. doi: 10.1016/S1470-2045(20)30096-6

53. Sirintrapun SJ, Lopez AM. Telemedicine in cancer care. Am Soc Clin Oncol Educ Book. (2018) 38:540-5. doi: 10.1200/EDBK_200141

54. Chuchu N, Dinnes J, Takwoingi Y, Matin RN, Bayliss SE, Davenport C, et al. Teledermatology for diagnosing skin cancer in adults. Cochrane Database Syst Rev. (2018) 12:Cd013193. doi: 10.1002/14651858.CD013193

55. Chee RI, Darwish D, Fernandez-Vega A, Patel S, Jonas K, Ostmo S, et al. Retinal telemedicine. Curr Ophthalmol Rep. (2018) 6:36-45. doi: 10.1007/s40135-018-0161-8

56. Subbaraman R, de Mondesert L, Musiimenta A, Pai M, Mayer KH, Thomas $\mathrm{BE}$, et al. Digital adherence technologies for the management of tuberculosis therapy: mapping the landscape and research priorities. BMJ Glob Health. (2018) 3:e001018. doi: 10.1136/bmjgh-2018-001018

57. Macaraig M, Lobato MN, McGinnis Pilote K, Wegener D. A national survey on the use of electronic directly observed therapy for treatment of tuberculosis. J Public Health Manag Pract. (2018) 24:567-70. doi: 10.1097/PHH.0000000000000627

58. Ambrosino N, Vitacca M, Dreher M, Isetta V, Montserrat JM, Tonia $\mathrm{T}$, et al. Tele-monitoring of ventilator-dependent patients: a European Respiratory Society Statement. Eur Respir J. (2016) 48:648-63. doi: 10.1183/13993003.01721-2015

59. Kovacevic P, Dragic S, Kovacevic T, Momcicevic D, Festic E, Kashyap R, et al. Impact of weekly case-based tele-education on quality of care in a limited resource medical intensive care unit. Crit Care. (2019) 23:220. doi: 10.1186/s13054-019-2494-6

60. Blakey JD, Bender BG, Dima AL, Weinman J, Safioti G, Costello RW. Digital technologies and adherence in respiratory diseases: the road ahead. Eur Respir J. (2018) 52:1801147. doi: 10.1183/13993003.01147-2018

61. Vitacca M, Montini A, Comini L. How will telemedicine change clinical practice in chronic obstructive pulmonary disease? Ther Adv Respir Dis. (2018) 12:1753465818754778. doi: 10.1177/1753465818754778

62. Ambrosino N, Fracchia C. The role of tele-medicine in patients with respiratory diseases. Expert Rev Respir Med. (2017) 11:893-900. doi: 10.1080/17476348.2017.1383898

63. Bruyneel M. Telemedicine in the diagnosis and treatment of sleep apnoea. Eur Respir Rev. (2019) 28:180093. doi: 10.1183/16000617.0093-2018

64. Gurbeta L, Badnjevic A, Maksimovic M, Omanovic-Miklicanin E, Sejdic E. A telehealth system for automated diagnosis of asthma and chronical obstructive pulmonary disease. J Am Med Inform Assoc. (2018) 25:1213-7. doi: 10.1093/jamia/ocy055

65. Majumder S, Deen MJ. Smartphone sensors for health monitoring and diagnosis. Sensors. (2019) 19:2164. doi: 10.3390/s19092164

66. Pépin JL, Tamisier R, Hwang D, Mereddy S, Parthasarathy S. Does remote monitoring change OSA management and CPAP adherence? Respirology. (2017) 22:1508-17. doi: 10.1111/resp.13183

67. Turino C, de Batlle J, Woehrle H, Mayoral A, Castro-Grattoni AL, Gómez $\mathrm{S}$, et al. Management of continuous positive airway pressure treatment compliance using telemonitoring in obstructive sleep apnoea. Eur Respir J. (2017) 49:1601128. doi: 10.1183/13993003.01128-2016

68. Munafo D, Hevener W, Crocker M, Willes L, Sridasome S, Muhsin Ma. A telehealth program for CPAP adherence reduces labor and yields similar adherence and efficacy when compared to standard of care. Sleep Breath. (2016) 20:777-85. doi: 10.1007/s11325-015-1298-4

69. Hobson E, Baird W, Bradburn M, Cooper C, Mawson S, Quinn $A$, et al. Process evaluation and exploration of telehealth in motor 
neuron disease in a UK specialist centre. BMJ Open. (2019) 9:e028526. doi: 10.1136/bmjopen-2018-028526

70. Basiri K, Ansari B, Okhovat AA. Life-threatening misdiagnosis of bulbar onset myasthenia gravis as a motor neuron disease: How much can one rely on exaggerated deep tendon reflexes. Adv Biomed Res. (2015) 4:58. doi: 10.4103/2277-9175.151874

71. Chahin N, Klein C, Mandrekar J, Sorenson E. Natural history of spinal-bulbar muscular atrophy. Neurology. (2008) 70:1967-71. doi: 10.1212/01.wnl.0000312510.49768.eb

72. Jaeger B, Bosch AM. Clinical presentation and outcome of riboflavin transporter deficiency: mini review after five years of experience. J Inherit Metab Dis. (2016) 39:559-64. doi: 10.1007/s10545-0169924-2

73. Chen Y, Chen Y, Zheng K, Dodakian L, See J, Zhou R, et al. A qualitative study on user acceptance of a home-based stroke telerehabilitation system. Top Stroke Rehabil. (2020) 27:81-92. doi: 10.1080/10749357.2019.16 83792

74. Sarfo FS, Ulasavets U, Opare-Sem OK, Ovbiagele B. Tele-rehabilitation after stroke: an updated systematic review of the literature. J Stroke Cerebrovasc Dis. (2018) 27:2306-18. doi: 10.1016/j.jstrokecerebrovasdis.2018. 05.013

75. Block VA, Pitsch E, Tahir P, Cree BA, Allen DD, Gelfand JM. Remote physical activity monitoring in neurological disease: a systematic review. PLOS ONE. (2016) 11:e0154335. doi: 10.1371/journal.pone.0 154335

76. Martinez RN, Hogan TP, Lones K, Balbale S, Scholten J, Bidelspach D, et al. Evaluation and treatment of mild traumatic brain injury through the implementation of clinical video telehealth: provider perspectives from the Veterans Health Administration. $\quad P M \quad R . \quad$ (2017) 9:231-40. doi: 10.1016/j.pmrj.2016. 07.002

77. Dams-O'Connor K, Sy KTL, Landau A, Bodien Y, Dikmen S, Felix ER, et al. The Feasibility of telephone-administered cognitive testing in individuals 1 and 2 years after inpatient rehabilitation for traumatic brain injury. J Neurotrauma. (2018) 35:1138-45. doi: 10.1089/neu.20 17.5347

78. O'Neil J, van Ierssel J, Sveistrup H. Remote supervision of rehabilitation interventions for survivors of moderate or severe traumatic brain injury: a scoping review. J Telemed Telecare. (2019) 1357633x19845466. doi: $10.1177 / 1357633 \times 19845466$

79. Selzler AM, Wald J, Sedeno M, Jourdain T, Janaudis-Ferreira $T$, Goldstein $\mathrm{R}$, et al. Telehealth pulmonary rehabilitation: a review of the literature and an example of a nationwide initiative to improve the accessibility of pulmonary rehabilitation. Chron Respir Dis. (2018) 15:41-7. doi: $10.1177 / 1479972317724570$

80. Hernandez C, Mallow J, Narsavage GL. Delivering telemedicine interventions in chronic respiratory disease. Breathe. (2014) 10:198. doi: $10.1183 / 20734735.008314$

81. World Health Organization (WHO). Noncommunicable Diseases and their Risk Factors. Available online at: https://www.who.int/ncds/management/ palliative-care/en/ (accessed April 16, 2020).

82. Fisher E, Hasselberg M, Conwell Y, Weiss L, Padrón NA, Tiernan E, et al. Telementoring primary care clinicians to improve geriatric mental health care. Popul Health Manag. (2017) 20:342-7. doi: 10.1089/pop.201 6.0087

83. White C, Mcllfatrick S, Dunwoody L, Watson M. Supporting and improving community health services-a prospective evaluation of ECHO technology in community palliative care nursing teams. BMJ Support Palliat Care. (2019) 9:202. doi: 10.1136/bmjspcare-2015-000935

84. Blanco C, Wall MM, Olfson M. Psychological aspects of the COVID19 pandemic. J Gen Intern Med. (2020). doi: 10.1007/s11606-02005955-3

85. Chan S, Parish M, Yellowlees P. Telepsychiatry today. Curr Psychiatry Rep. (2015) 17:89. doi: 10.1007/s11920-015-0630-9

86. Fortney JC, Pyne JM, Turner EE, Farris KM, Normoyle TM, Avery $\mathrm{MD}$, et al. Telepsychiatry integration of mental health services into rural primary care settings. Int Rev Psychiatry. (2015) 27:525-39. doi: $10.3109 / 09540261.2015 .1085838$
87. Chan S, Godwin H, Gonzalez A, Yellowlees PM, Hilty DM. Review of use and integration of mobile apps into psychiatric treatments. Curr Psychiatry Rep. (2017) 19:96. doi: 10.1007/s11920-017-0 848-9

88. DeJong SM. Professionalism and technology: competencies across the tele-behavioral health and E-behavioral health spectrum. Acad Psychiatry. (2018) 42:800-7. doi: 10.1007/s40596-0180947-x

89. European Commission. 2018 Ageing Report: Policy Challenges for Ageing Societies. Available online at: https://ec.europa.eu/info/news/economyfinance/policy-implications-ageing- examined-new-report-2018-may-25_ en (accessed June 18, 2020).

90. van Houwelingen CT, Ettema RG, Antonietti MG, Kort HS. Understanding older people's readiness for receiving telehealth: mixedmethod study. J Med Internet Res. (2018) 20:e123. doi: 10.2196/jmi r. 8407

91. CDC. COVID-19 response team. severe outcomes among patients with coronavirus disease 2019 (COVID-19) - United States, February 12March 16, 2020. MMWR Morb Mortal Wkly Rep. (2020) 69:343-6. doi: 10.15585/mmwr.mm6912e2

92. McMichael TM, Currie DW, Clark S, Pogosjans S, Kay M, Schwartz NG, et al. Epidemiology of Covid-19 in a long-term care facility in king county, Washington. N Engl J Med. (2020) 382:2005-11. doi: 10.1056/NEJMoa2005412

93. Booth R. Half of Coronavirus Deaths Happen in Care Homes, Data from EU Suggests. Available online at: https://www.theguardian.com/world/2020/ apr/13/half-of-coronavirus- deaths-happen-in-care-homes-data-from-eusuggests (accessed April 16, 2020).

94. Serpen G, Khan R. Real-time detection of human falls in progress: machine learning approach. Proc Comput Sci. (2018) 140:238-47. doi: $10.1016 /$ j.procs.2018.10.324

95. Harerimana B, Forchuk C, O'Regan T. The use of technology for mental healthcare delivery among older adults with depressive symptoms: a systematic literature review. Int J Ment Health Nurs. (2019) 28:657-70. doi: $10.1111 /$ inm. 12571

96. Porritt A. What Will Happen if Coronavirus Enters a Refugee Camp? Available online at: https://www.unicef.org.au/blog/unicef-in-action/april2020/coronavirus-refugees (accessed on June 17, 2020).

97. Truelove S, Abrahim O, Altare C, Lauer SA, Grantz KH, Azman AS, et al. The potential impact of COVID-19 in refugee camps in Bangladesh and beyond: a modeling study. PLoS Med. (2020) 17:e1003144. doi: 10.1371/journal.pmed.1003144

98. Hassan A, Sharif K. Efficacy of telepsychiatry in refugee populations: a systematic review of the evidence. Cureus. (2019) 11:e3984. doi: 10.7759/cureus. 3984

99. Chipps J, Brysiewicz P, Mars M. Effectiveness and feasibility of telepsychiatry in resource constrained environments? A systematic review of the evidence. Afr J Psychiatry. (2012) 15:235-43. doi: 10.4314/ajpsy.v15i4.30

100. O’Reilly R, Bishop J, Maddox K, Hutchinson L, Fisman M, Takhar J. Is telepsychiatry equivalent to face-to-face psychiatry? Results from a randomized controlled equivalence trial. Psychiatr Serv. (2007) 58:836-43. doi: 10.1176/ps.2007.58.6.836

101. Smith AC, Thomas E, Snoswell CL, Haydon H, Mehrotra A, Clemensen J, et al. Telehealth for global emergencies: Implications for coronavirus disease 2019 (COVID-19). J Telemed Telecare. (2020) 26:309-13. doi: 10.1177/1357633X20916567

102. Sayani S, Muzammil M, Saleh K, Muqeet A, Zaidi F, Shaikh T. Addressing cost and time barriers in chronic disease management through telemedicine: an exploratory research in select low- and middleincome countries. Ther Adv Chronic Dis. (2019) 10:2040622319891587. doi: $10.1177 / 2040622319891587$

103. Michaud TL, Zhou J, McCarthy MA, Siahpush M, Su D. Costs of home-based telemedicine programs: a systematic review. Int J Technol Assess Health Care. (2018) 34:410-8. doi: 10.1017/S0266462318000454

104. Brennan JA, Kealy JA, Gerardi LH, Shih R, Allegra J, Sannipoli L, et al. Telemedicine in the emergency department: a randomized controlled trial. J Telemed Telecare. (1999) 5:18-22. doi: 10.1258/13576339919 32342 
105. Dharmar M, Romano PS, Kuppermann N, Nesbitt TS, Cole SL, Andrada $\mathrm{ER}$, et al. Impact of critical care telemedicine consultations on children in rural emergency departments. Crit Care Med. (2013) 41:2388-95. doi: 10.1097/CCM.0b013e31828e9824

106. Molinari G, Reboa G, Frascio M, Leoncini M, Rolandi A, Balzan C, et al. The role of telecardiology in supporting the decision-making process of general practitioners during the management of patients with suspected cardiac events. J Telemed Telecare. (2002) 8:97-101. doi: 10.1258/13576330219 37541

107. Khader YS, Jarrah MI, Al-Shudifat AE, Shdaifat A, Aljanabi H, Al-Fakeh SI, et al. Telecardiology application in Jordan: its impact on diagnosis and disease management, patients' quality of life, and time- and costsavings. Int J Telemed Appl. (2014) 2014:819837. doi: 10.1155/2014/ 819837

108. Scalvini S, Zanelli E, Volterrani M, Castorina M, Giordano A, Glisenti F. Potential cost reductions for the National Health Service through a telecardiology service dedicated to general practice physicians. Ital Heart J Suppl. (2001) 2:1091-7.

109. Sable CA, Cummings SD, Pearson GD, Schratz LM, Cross RC, Quivers ES, et al. Impact of telemedicine on the practice of pediatric cardiology in community hospitals. Pediatrics. (2002) 109:E3. doi: 10.1542/peds. 109.1.e3

110. Capozzo R, Zoccolella S, Musio M, Barone R, Accogli M, Logroscino G. Telemedicine is a useful tool to deliver care to patients with Amyotrophic Lateral Sclerosis during COVID-19 pandemic: results from Southern Italy. Amyotroph Lateral Scler Frontotemporal Degener. (2020) 1-7. doi: 10.1080/21678421.2020.1773502

111. Ohta Y, Yamashita T, Hishikawa N, Sato K, Hatanaka N, Takemoto M, et al. Affective improvement of neurological disease patients and caregivers using an automated telephone call service. J Clin Neurosci. (2018) 56:74-8. doi: 10.1016/j.jocn.2018.07.006

112. Medeiros de Bustos E, Berthier E, Chavot D, Bouamra B, Moulin T. Evaluation of a French regional telemedicine network dedicated to neurological emergencies: a 14-year study. Telemed J E Health. (2018) 24:155-60. doi: 10.1089/tmj.2017.0035

113. Vatankhah B, Schenkel J, Fürst A, Haberl RL, Audebert HJ. Telemedically provided stroke expertise beyond normal working hours. The telemedical project for integrative stroke care. Cerebrovasc Dis. (2008) 25:332-7. doi: 10.1159/000118378

114. Lyerly MJ, Wu TC, Mullen MT, Albright KC, Wolff C, Boehme AK, et al. The effects of telemedicine on racial and ethnic disparities in access to acute stroke care. J Telemed Telecare. (2016) 22:114-20. doi: $10.1177 / 1357633 X 15589534$

115. Dharmasaroja PA, Muengtaweepongsa S, Kommarkg U. Implementation of Telemedicine and Stroke Network in thrombolytic administration: comparison between walk-in and referred patients. Neurocrit Care. (2010) 13:62-6. doi: 10.1007/s12028-010-9360-3

116. Schwab S, Vatankhah B, Kukla C, Hauchwitz M, Bogdahn U, Fürst A, et al. Long-term outcome after thrombolysis in telemedical stroke care. Neurology. (2007) 69:898-903. doi: 10.1212/01.wnl.0000269671.08423.14

117. Yang CP, Hunt EA, Shilkofski N, Dudas R, Egbuta C, Schwartz JM. Can telemedicine improve adherence to resuscitation guidelines for critically Ill children at community hospitals? A randomized controlled trial using high-fidelity simulation. Pediatr Emerg Care. (2017) 33:474-9. doi: 10.1097/PEC.0000000000000653

118. Kuipers E, Poot CC, Wensing M, Chavannes NH, de Smet PA, Teichert M. Self-management maintenance inhalation therapy with eHealth (SELFIE): observational study on the use of an electronic monitoring device in respiratory patient care and research. J Med Internet Res. (2019) 21:e13551. doi: 10.2196/13551

119. Orozco-Beltran D, Sánchez-Molla M, Sanchez JJ, Mira JJ, ValCrònic Research G. Telemedicine in primary care for patients with chronic conditions: the ValCrònic Quasi-Experimental study. J Med Inter Res. (2017) 19:e400. doi: 10.2196/jmir.7677

120. Doñate-Martínez A, Ródenas F, Garcés J. Impact of a primary-based telemonitoring programme in HRQOL, satisfaction and usefulness in a sample of older adults with chronic diseases in Valencia (Spain). Arch Gerontol Geriatr. (2016) 62:169-75. doi: 10.1016/j.archger.2015.09.008
121. Martín-Lesende I, Orruño E, Bilbao A, Vergara I, Cairo MC, Bayón JC, et al. Impact of telemonitoring home care patients with heart failure or chronic lung disease from primary care on healthcare resource use (the TELBIL study randomised controlled trial). BMC Health Serv Res. (2013) 13:118. doi: 10.1186/1472-6963-13-118

122. Palmieri V, Pezzullo S, Lubrano V, Bettella S, Olandese M, Sorrentino C, et al. [Home-based telemonitoring of simple vital signs to reduce hospitalization in heart failure patients: real-world data from a community-based hospital]. G Ital Cardiol. (2011) 12:829-36. doi: 10.1714/996.10828

123. Pinto A, Almeida JP, Pinto S, Pereira J, Oliveira AG, de Carvalho M. Home telemonitoring of non-invasive ventilation decreases healthcare utilisation in a prospective controlled trial of patients with amyotrophic lateral sclerosis. J Neurol Neurosurg Psychiatry. (2010) 81:1238-42. doi: 10.1136/jnnp.2010.206680

124. Paganoni S, van de Rijn M, Drake K, Burke K, Doyle M, Ellrodt AS, et al. Adjusted cost analysis of video televisits for the care of people with amyotrophic lateral sclerosis. Muscle Nerve. (2019) 60:147-54. doi: $10.1002 /$ mus.26606

125. Rawstorn JC, Gant N, Direito A, Beckmann C, Maddison R. Telehealth exercise-based cardiac rehabilitation: a systematic review and meta-analysis. Heart. (2016) 102:1183-92. doi: 10.1136/heartjnl-2015-308966

126. Kuntz JG, Kavalieratos D, Esper GJ, Ogbu N, Jr., Mitchell J, Ellis CM, et al. Feasibility and acceptability of inpatient palliative care E-family meetings during COVID-19 pandemic. J Pain Symptom Manage. (2020). doi: 10.1016/j.jpainsymman.2020.06.001

127. Nemecek R, Huber P, Schur S, Masel EK, Baumann L, Hoeller C, et al. Telemedically augmented palliative care: Empowerment for patients with advanced cancer and their family caregivers. Wien Klin Wochenschr. (2019) 131:620-6. doi: 10.1007/s00508-019-01562-3

128. Ruskin PE, Silver-Aylaian M, Kling MA, Reed SA, Bradham DD, Hebel JR, et al. Treatment outcomes in depression: comparison of remote treatment through telepsychiatry to in-person treatment. Am J Psychiatry. (2004) 161:1471-6. doi: 10.1176/appi.ajp.161.8.1471

129. Salisbury C, O'Cathain A, Edwards L, Thomas C, Gaunt D, Hollinghurst S, et al. Effectiveness of an integrated telehealth service for patients with depression: a pragmatic randomised controlled trial of a complex intervention. Lancet Psychiatry. (2016) 3:515-25. doi: 10.1016/S2215-0366(16)00083-3

130. Ateriya N, Saraf A, Meshram VP, Setia P. Telemedicine and virtual consultation: The Indian perspective. Natl Med J India. (2018) 31:215-8. doi: 10.4103/0970-258X.258220

131. Park LG, Howie-Esquivel J, Dracup K. A quantitative systematic review of the efficacy of mobile phone interventions to improve medication adherence. $J$ Adv Nurs. (2014) 70:1932-53. doi: 10.1111/jan.12400

132. Hall AK, Cole-Lewis H, Bernhardt JM. Mobile text messaging for health: a systematic review of reviews. Annu Rev Public Health. (2015) 36:393-415. doi: 10.1146/annurev-publhealth-031914-122855

133. Zheng X, Spatz ES, Bai X, Huo X, Ding Q, Horak P, et al. Effect of text messaging on risk factor management in patients with coronary heart disease: the CHAT randomized clinical trial. Circ Cardiovasc Qual Outcomes. (2019) 12:e005616. doi: 10.1161/CIRCOUTCOMES.119.005616

134. Huo X, Spatz ES, Ding Q, Horak P, Zheng X, Masters C, et al. Design and rationale of the Cardiovascular Health and Text Messaging (CHAT) study and the CHAT-Diabetes Mellitus (CHAT-DM) study: two randomised controlled trials of text messaging to improve secondary prevention for coronary heart disease and diabetes. BMJ Open. (2017) 7:e018302. doi: 10.1136/bmjopen-2017-018302

135. Mehraeen E, Safdari R, Mohammadzadeh N, Seyedalinaghi SA, Forootan S, Mohraz M. Mobile-based applications and functionalities for selfmanagement of people living with HIV. Stud Health Technol Inform. (2018) 248:172-9.

136. Mbuagbaw L, Mursleen S, Lytvyn L, Smieja M, Dolovich L, Thabane L. Mobile phone text messaging interventions for HIV and other chronic diseases: an overview of systematic reviews and framework for evidence transfer. BMC Health Serv Res. (2015) 15:33. doi: 10.1186/s12913-0140654-6

137. Mair F, Whitten P. Systematic review of studies of patient satisfaction with telemedicine. BMJ. (2000) 320:1517. doi: 10.1136/bmj.320.7248.1517 
138. Freir V, Kirkwood K, Peck D, Robertson S, Scott-Lodge L, Zeffert S. Telemedicine for clinical psychology in the Highlands of Scotland. J Telemed Telecare. (1999) 5:157-61. doi: 10.1258/1357633991933567

139. Donelan K, Barreto EA, Sossong S, Michael C, Estrada JJ, Cohen AB, et al. Patient and clinician experiences with telehealth for patient follow-up care. Am J Manag Care. (2019) 25:40-4.

140. Gordon HS, Solanki P, Bokhour BG, Gopal RK. "I'm not feeling like I'm part of the conversation" patients' perspectives on communicating in clinical video telehealth visits. J Gen Intern Med. (2020) 35:1751-8. doi: 10.1007/s11606-020-05673-w

141. Williams TL, May CR, Esmail A. Limitations of patient satisfaction studies in telehealthcare: a systematic review of the literature. Telemed J e-Health. (2001) 7:293-316. doi: 10.1089/153056201528 14700

142. American Academy of Neurology (AAn). Telemedicine and COVID-19 Implementation Guide. Available online at: https://www.aan.com/toolsand-resources/practicing-neurologists-administrators/telemedicine-andremote-care/ (accessed on June 17, 2020).
Conflict of Interest: SP is the Vice President of Immersive Medicine at Luxsonic technologies, a medical technology company specializing in virtual/augmented reality for medical education, collaboration, and training. The opinions expressed in this article are those of the authors and do not necessarily represent the decisions, official policy, or opinions of the affiliated institutions.

The remaining authors declare that the research was conducted in the absence of any commercial or financial relationships that could be construed as a potential conflict of interest.

Copyright (ㅇ 2020 Bhaskar, Bradley, Chattu, Adisesh, Nurtazina, Kyrykbayeva, Sakhamuri, Moguilner, Pandya, Schroeder, Banach and Ray. This is an open-access article distributed under the terms of the Creative Commons Attribution License (CC $B Y)$. The use, distribution or reproduction in other forums is permitted, provided the original author(s) and the copyright owner(s) are credited and that the original publication in this journal is cited, in accordance with accepted academic practice. No use, distribution or reproduction is permitted which does not comply with these terms. 